\title{
Cytogenetic divergence between two sympatric species of Characidium (Teleostei, Characiformes, Crenuchidae) from the Machado River, Minas Gerais, Brazil
}

\author{
Alexandre Rodrigues da Silva and Edson Luis Maistro \\ UNESP - Universidade Estadual Paulista, Departamento de Fonoaudiologia, Marília, SP, Brazil.
}

\begin{abstract}
Cytogenetic studies were performed on two sympatric species of Characidium, C. gomesi and C. cf. zebra, from the Grande River basin, Minas Gerais State, Brazil. Although both species had a chromosome number of 50 with a karyotype exclusively consisting of meta- and submetacentric chromosomes, interspecific diversity was detected concerning the size of the two first chromosome pairs of the karyotypes. Active nucleolus organizer regions (NORs) were located at the terminal position on the long arm of the $17^{\text {th }}$ pair of $C$. gomesi and at subterminal position on the long arm of the $23^{\text {rd }}$ pair of $C$. cf. zebra. For both species the fluorochrome $\mathrm{CMA}_{3}$ stained only the NOR-bearing pair of chromosomes. The heterochromatin pattern also showed some differentiation between these species restricted to the centromeric or pericentromeric region of $C$. cf. zebra and practically absent in $C$. gomesi. These data are discussed concerning chromosome diversification in this fish group.
\end{abstract}

Key words: Characidium gomesi, Characidium cf. zebra, Crenuchidae, NOR-banding, C-banding.

Received: June 9, 2005; Accepted: November 16, 2005.

\section{Introduction}

The genus Characidium (family Crenuchidae) is made up of small fish which rarely exceed a standard length of $10 \mathrm{~cm}$ and which usually occur in small headwater streams. However, little is known about the chromosomes of the fish in the Crenuchidae despite the fact that this family includes about 80 nominal species (Buckup, 1993a), with the genus Characidium alone including 59 nominal taxa which makes it the most diverse genus in the Crenuchidae (Buckup, 1993a, b).

The genus Characidium is also the most cytogenetically studied Crenuchidae genera, with cytogenetic data being available on five Characidium cf. zebra populations (Miyazawa and Galetti-Jr., 1994; Maistro et al., 1998a; Centofante et al., 2001), one population published as Characidium cf. fasciatum and reidentified as Characidium sp. aff. Characidium zebra; another as Characidium cf. lagosantensis (Miyazawa and Galetti-Jr., 1994); one as Characidium pterostictum (Miyazawa and Galetti-Jr., 1994); one as Characidium sp. (Miyazawa and Galetti-Jr., 1994); two populations of Characidium gomesi,

Send correspondence to Edson Luis Maistro. Departamento de Fonoaudiologia, Universidade Estadual Paulista, Av Hygino Muzzi Filho 737, Caixa Postal 181, 17525-900, Marília, SP, Brazil. E-mail: maistroedson@yahoo.com.br. one published as $C$. cf. fasciatum and reidentified as Characidium sp. cf. Characidium gomesi (Maistro et al., 1998a; Centofante et al., 2001; Maistro et al., 2004) and the other as Characidium lauroi (Centofante et al., 2003); and one population of Characidium sp. cf. Characidium alipioi (Centofante et al., 2003). All these Characidium species/populations present a relatively stable karyotypic macrostructure, with a diploid number of $2 n=50$ and biarmed chromosomes which are usually meta-submetacentric. Exception to this diploid chromosome number was observed in a Passa-Cinco River (Brazil) Characidium cf. zebra specimen which presented one B-chromosome in some cells (Venere et al., 1999), in Quinta and Pardo River (Brazil) C. gomesi specimens with 0 to 4 supernumerary chromosomes (Maistro et al., 1998a; 2004) and in a Paiol Grande stream (Brazil) triploid C. gomesi specimen (Centofante et al., 2001). Although Characidium have demonstrated a constant diploid number of chromosomes, the karyotype structure is variable regarding chromosome shape, sex chromosome systems and number and position of the silver nitrate stained nucleolar organizer region (AgNOR) and heterochromatin (Miyazawa and Galetti-Jr., 1994, Maistro et al., 1998a; Centofante et al., 2001; 2003; Maistro et al., 2004).

Since there is no cytogenetic data on Characidium from the Minas Gerais region of Brazil, the main objective 
of the present study was to describe the karyotype structure of two sympatric Characidium species from the south of Minas Gerais State. The data obtained are discussed concerning some aspects related to the chromosomal evolution of this genus.

\section{Material and Methods}

A cytogenetic survey was performed on two sympatric Characidium species: 14 female and 6 male $(\mathrm{n}=20)$ Characidium gomesi and 10 female and 3 male $(\mathrm{n}=13)$ Characidium cf. zebra collected in the Machado River at $22^{\circ} 04.471^{\prime} \mathrm{S} ; 46^{\circ} 02.810^{\prime} \mathrm{W}$ near the town of São João da Mata in the Brazilian State of Minas Gerais. Voucher specimens are deposited at the fish collection of the Brazilian National Museum (Museu Nacional Rio de Janeiro, MNRJ) under catalog numbers MNRJ 28408 for C. cf. zebra and MNRJ 28411 for C. gomesi).

Mitotic cells were obtained from gill and kidney tissues by the technique described by Foresti et al. (1993). Chromosome morphology was determined on the basis of arm ratios as proposed by Levan et al. (1964) and the chromosomes were classified as metacentric (M) and submetacentric (SM) and were paired in decreasing order of size. C-banding was performed by the method of Sumner (1972), and silver-staining of the nucleolus organizer regions (Ag-NORs) was performed by the technique of Howell and Black (1980). Chromomycin $\mathrm{A}_{3}\left(\mathrm{CMA}_{3}\right)$ staining was performed by the method of Schweizer (1980).

\section{Results}

Giemsa staining showed that the specimens of both Characidium species investigated presented the same basic karyotype of $2 \mathrm{n}=50(32 \mathrm{M}+18 \mathrm{SM})$ with the fundamental number (i.e. the number of chromosomal arms) being equal to 100 (Figures 1a and 1b). However, the first metacentric chromosome pair of $C$. cf. zebra was considerably larger than the second pair while in the $C$. gomesi specimens the first and the second metacentric chromosome pair were similar in size. In C. cf. zebra we observed a secondary constriction at the subterminal position on the long arm of the $23^{\text {th }}$ chromosome pair (Figure 1b). No chromosome differences were observed between males and females of both species.

The Ag-NOR analysis of both Characidium species showed the presence of only one chromosome pair with active NORs. Terminal NORs were observed on the long arm of a pair of major submetacentric chromosomes (pair 17) in C. gomesi (Figure 2a) and on the subterminal position on the long arm of the small-sized submetacentric (pair 23), coinciding with the region of secondary constriction in $C$. cf. zebra (Figure $2 \mathrm{~b}$ ). In both species, chromomycin $\mathrm{A}_{3}$ showed fluorescence only at the NOR sites (Figures $2 \mathrm{c}$ and 2d).

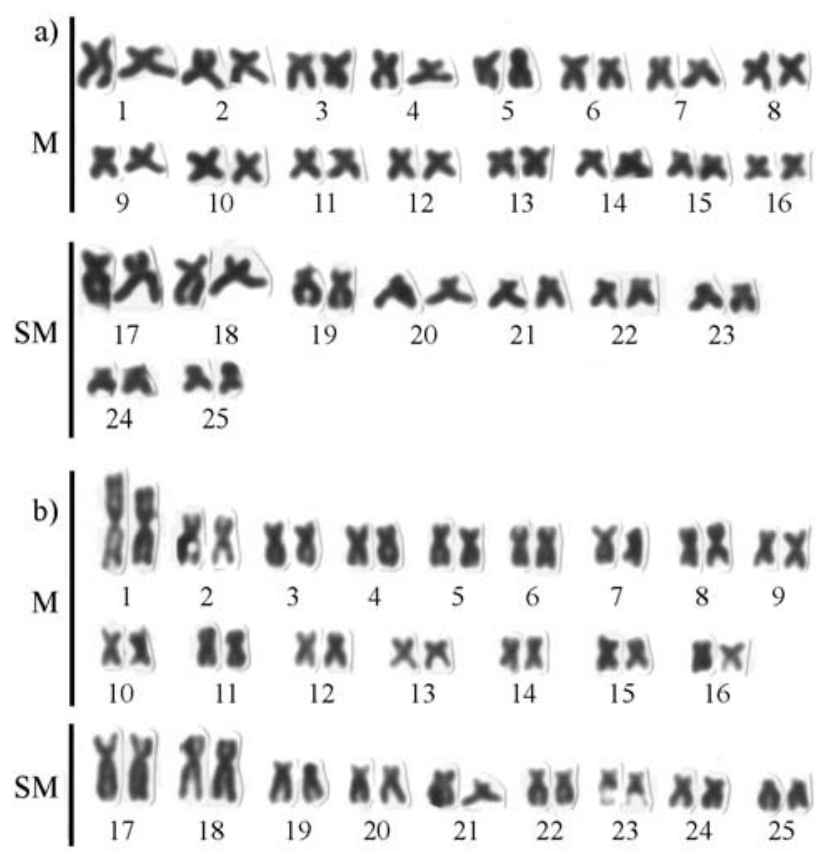

Figure 1 - Karyotypes of (a) Characidium gomesi and (b) Characidium cf. zebra from the Machado River after conventional Giemsa staining.



Figure 2 - Somatic metaphases of Characidium gomesi (a and b) and Characidium cf. zebra (c and d) from the Machado River, after silver nitrate ( $\mathrm{a}$ and $\mathrm{c}$ ) and $\mathrm{CMA}_{3}$ staining ( $\mathrm{b}$ and $\mathrm{d}$ ). The arrows point NORbearing chromosomes.

The C-banding pattern showed heterochromatic blocks at the centromeric or pericentromeric regions of all Characidium cf. zebra chromosomes and in the subterminal position of the $23^{\text {th }}$ chromosome pair (Figure 3 a) while C. gomesi showed small heterochromatin blocks distributed at the centromeres and telomeres of a few chromosomes, including the telomeric region of the long arm of the $17^{\text {th }}$ chromosome pair (Figure $3 \mathrm{~b}$ ). 

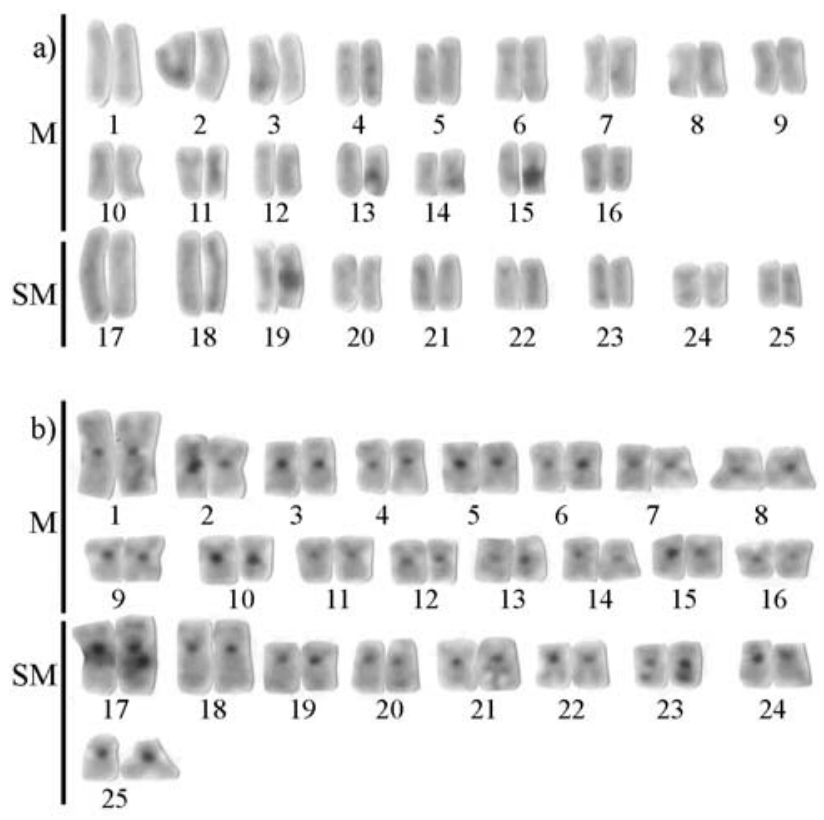

Figure 3 - C-banding Karyotypes of (a) Characidium gomesi and (b) Characidium cf. zebra from the Machado River.

\section{Discussion}

The Characicium cf. zebra and C. gomesi specimens from the Machado River presented the same diploid chromosome number of $2 \mathrm{n}=50$, distributed as 32 metacentric and 18 submetacentric chromosomes. This karyotype macrostructure is the same as that observed in the majority of the other Characidium species or populations analyzed, with the exception of $C$. pterostictum from the Carlos Botelho Ecological Station in the Brazilian state of São Paulo (Miyazawa and Galetti-Jr., 1994) and C. lauroi from the Grande stream, also in São Paulo state, (Centofante et al., 2003) which presented one subtelocentric chromosome pair and few differences in the number of meta- submetacentric chromosomes.

The $C$. cf. zebra and $C$. gomesi specimens studied by us could be easily separated by the fact that the $C$. cf. zebra first metacentric chromosome pair is larger than the second pair while the $C$. gomesi first metacentric pairs were homogeneous in size. Except for Characidium. sp. cf. Characidium alipioi and C. lauroi (Centofante et al., 2003) and the $C$. gomesi described in the present paper, the great majority of the Characidium species so far studied have a first metacentric pair which is considerably larger than their second metacentric pair. According to Buckup (1993b) $C$. zebra are morphologically primitive and occupy a basal position in the phylogeny of Characidium, so the presence of a large first metacentric pair in Characidium cf. zebra could be considered primitive for the Characidium species that present it, being derived the size homogenicity between the $1^{\text {th }}$ and $2^{\text {th }}$ metacentric chromosome pairs.
A similar karyotypic pattern has been observed in the cis-Andean genera Trichomycterus, made up of small fish that, like Characidium, are usually found isolated in the headwaters of small rivers. Sato et al. (2004) has shown that the Trichomycterus species florensis, reinhardti and auroguttatus form a group in which the first metacentric pair is considerably larger than the second metacentric pair, while Trichomycterus sp. aff. Trichomycterus itatiyae and Trichomycterus davisi form a group for which the first and second metacentric pairs are about the same size, although larger than the other metacentric pairs.

The position of the ribosome sites could clearly differentiate both Machado River populations, C. cf. zebra showing Ag-NOR sites in the subterminal position on the long arm of the $23^{\text {th }}$ small-sized submetacentric pair while C. gomesi presented Ag-NORs at the telomeric position on the long arm of the large submetacentric pair 17. Centofante et al. (2003) suggested that species of Characidium with a ZZ/ZW sex chromosome systems are more closely related among themselves than to species without such systems. This idea was specially based on the fact that only species of Characidium with sex chromosomes presented Ag-NORs in the terminal region of the long arm of a large submetacentric chromosome pair. The Ag-NOR characterization developed in our study showed that the Machado River C. gomesi are the only Characidium species with Ag-NORs on a large submetacentric chromosome and which do not have a sex chromosome system.

The cytogenetic information available in the literature for other Characidium species reports some species with a single chromosome pair bearing Ag-NORs and yet other species with multiple ribosomal sites. Variation in the number of chromosomes bearing Ag-NOR regions is a common feature among characid fishes which has been reported by a number of authors using the Ag-NOR technique (e.g. Almeida-Toledo and Foresti, 1985; Wasko et al., 1996; Jesus and Moreira-Filho, 2003). Maistro et al. (1998a) observed multiple Ag-NORs in some Pardo River Characidium specimens, however subsequent $18 \mathrm{~S}$ rDNA FISH analysis of the chromosomes of the 4 specimens showed only one pair bearing ribosomal sites (Maistro et al., 2004). The variable number of ribosomal sites found in the Pardo River population could suggest the occurrence of inter-individual numerical polymorphism of the NOR sites, as has been observed for the Prochilodus lineatus chromosome complement (Maistro et al., 2004; Jesus and Moreira-Filho, 2003).

The majority of the Characidium species analyzed by us showed Ag-NORs located on small or medium-sized submetacentric chromosomes and, with exception of $C$. lauroi, the Ag-NORs were always located on the long arm. It thus seems that in addition to having a diploid chromosome number of $2 \mathrm{n}=50$ the location of Ag-NORs almost exclusively on the long arm of the chromosomes is another 
feature common to Characidium. The fact that sympatric Characidium species always showed Ag-NORs on different chromosome pairs (Centofante et al., 2001; 2003; present paper) indicates that NOR location is an important cytotaxonomic tool for this group. It may be that FISH analysis with rDNA probes could help in the better understanding of the pattern distribution of ribosome sites on Characidium chromosomes.

We found that the Ag-NOR sites were positively stained by the $\mathrm{CMA}_{3}$ fluorochrome (Figure 2b), suggesting that the rDNA loci of both Characidium species studied in may contain spacer sequences or NOR-associated heterochromatin rich in GC base pairs. On the other hand, these data suggest that the $\mathrm{C}$-band positive segments found in both species are not rich in GC base pairs, a characteristic which has been commonly found in several fish species (Amemiya and Gold, 1986; Maistro et al., 2002; Fonseca et al., 2003; among others).

The C-banding pattern could also differentiate the two sympatric Characidium species studied by us. In both species heterochromatin preferentially appeared at the centromeres or in the pericentromeric regions but $C$. cf. $z e-$ bra presented more heterochromatin than C. gomesi, which also presented a few telomeric C-band positive blocks. Centromeric and/or pericentromeric heterochromatin has been observed in the majority of the Characidium species studied and, in smaller quantities, in C. gomesi from the Paiol Grande stream (Centofante et al., 2001) as well as in the C. sp. cf. C. gomesi from the Pardo River (published as C. cf. fasciatum by Maistro et al., 1998a) and C. gomesi studied by us. The available C-banding data shows that the Characidium taxa most related to gomesi present fewer heterochromatin-bearing chromosomes than other Characidium species.

Maistro et al. (1998a) described a ZZ/ZW sex-chromosome system for Pardo River C. gomesi, where the $\mathrm{Z}$ and $\mathrm{W}$ chromosome have the same shape and size and are differentiated from each other by the total amount of heterochromatinization of the $\mathrm{W}$ chromosome. Centofante et al. (2001) found a similar sex chromosome system in $C$. gomesi from the Paiol Grande stream, these fish also presenting high heterochromatinization of the $\mathrm{W}$ chromosome but in this case this chromosome was small in comparison to the $\mathrm{Z}$ chromosome. Since we detected no sex chromosome differentiation in C. gomesi and considering the fact that these fish live in headwaters, show low geographical mobility and form local populations, attributes can facilitate speciation, we feel that $C$. gomesi from the Machado River could represent a new Characidium species.

On the basis of the cytogenetic data available on Characidium species we suggest that the general trend of this group towards karyotypic diversification is similar to other fish groups that maintain a conserved karyotype macrostructure but that are quite divergent in terms of NOR location, heterochromatin distribution and the occurrence of sex chromosomes (Koehler et al., 1997; Pereira et al., 2002; for example). The specific characteristics observed in the chromosome structure of the genus Characidium are probably due to the fact that this nominal species is composed of isolated populations found in the headwaters of small tributaries, which probably followed different routes of chromosomal diversification. These characteristics make Characidium an excellent group for supplementing the evolutionary studies which have been carried out with Astyanax scabripinnis and Trichomycterus that have similar ecological characteristics (Moreira-Filho and Bertollo, 1991; Maistro et al., 1998b; Borin and Martins-Santos, 1999). Since only a few Characidium species have so far been investigated, further studies on other Characidium species and populations are necessary in order to better understand the processes underlying chromosome diversification in this group of fish.

\section{Acknowledgments}

The authors are grateful to Dr. Francisco Langeani Neto and to Dr. Paulo Buckup for the taxonomic identification of the species and to Dr. Orlando Moreira Filho for critical suggestions to this work. Funds supporting this study were provided by the Brazilian agencies FAPEMIG and UNIFENAS.

\section{References}

Almeida-Toledo LF and Foresti F (1985) As regiões organizadoras de nucléolos em peixes. Cienc Cult 37:448-453.

Amemiya CT and Gold JR (1986) Chromomycin A 3 stains nucleolus organizer regions of fish chromosomes. Copeia 1:226231.

Borin LA and Martins-Santos IC (1999) Karyotype characterization of three species of the genus Trychomycterus (Teleostei, Siluriformes) from Iguaçu River basin. Genetica 106:215221.

Buckup PA (1993a) The monophyly of Characidiinae, a neotropical group of Characiformes fishes (Teleostei, Ostariophysi). Zool J Linn Soc 108:225-245.

Buckup PA (1993b) Phylogenetic interrelationships and reductive evolution in neotropical Characidiinin fishes (Characiformes, Ostariophysi). Cladistics 9:305-341.

Centofante L, Bertollo LAC and Moreira-Filho O (2001) Comparative cytogenetics among sympatric species of Characidium (Pisces, Characiformes). Diversity analysis with the description of a ZW sex chromosome system and natural triploidy. Caryologia 54:253-260.

Centofante L, Bertollo LAC, Buckup PA and Moreira-Filho O (2003) Chromosomal divergence and maintenance of sympatric Characidium fish species (Crenuchidae, Characidiinae). Hereditas 138:213-218.

Fonseca YM, Oliveira C, Foresti F and Maistro EL (2003) First cytogenetic description of the species Rhamdella microcephala (Pisces, Hepapteridae). Cytologia 68:31-34.

Foresti F, Oliveira C and Almeida-Toledo LF (1993) A method for chromosome preparations from large fish specimens us- 
ing in vitro short-term treatment with colchicine. Experientia 49:810-813.

Howell WM and Black DA (1980) Controlled silver-staining of nucleolus organizer regions with a protective colloidal developer: A 1-step method. Experientia 36:1014-1015.

Jesus CM and Moreira-Filho O (2003) Chromosomal location of 5S and 18S rDNA genes in Prochilodus lineatus (Characiformes, Prochilodontidae). Caryologia 56:281-287.

Koehler MR, Dehm D, Guttenbach M, Nanda I, Haaf T, Molina WF, Galetti-Jr PM and Schmid M (1997) Cytogenetics of the genus Leporinus (Pisces, Anostomidae). 1. Karyotype analysis, heterochromatin distribution and sex chromosomes. Chrom Res 5:12-22.

Levan A, Fredga K and Sandberg AA (1964) Nomenclature for centromeric position on chromosomes. Hereditas 52:201220.

Maistro EL, Prieto-Mata E, Foresti F and Oliveira C (1998a) Unusual occurrence of a ZZ/ZW sex-chromosome system and supernumerary chromosomes in Characidium cf. fasciatum (Pisces, Characiformes, Characidiinae). Genetica 104:1-7.

Maistro EL, Oliveira C and Foresti F (1998b) Comparative cytogenetic and morphological analysis of Astyanax scabripinnis paranae (Pisces, Characidae, Tetragonopterinae). Genet Mol Biol 21:201-206.

Maistro EL, Oliveira C and Foresti F (2002) Cytogenetic analysis of A- and B-chromosomes of Rhamdia hilarii (Teleostei, Pimelodidae): C-banding, silver nitrate and $\mathrm{CMA}_{3}$ staining and restriction endonuclease banding. Cytologia 67:25-31.
Maistro EL, Jesus CM, Oliveira C, Moreira-Filho O and Foresti F (2004) Cytogenetic analysis of A-, B-chromosomes and ZZ/ZW sex chromosomes of Characidium gomesi (Teleostei, Characiformes, Crenuchidae). Cytologia 69:181-186.

Miyazawa CS and Galetti-Jr PM (1994) First cytogenetical studies in Characidium species (Pisces, Characiformes, Characidiinae). Cytologia 59:73-79.

Moreira-Filho O and Bertollo LAC (1991) Astyanax scabripinnis (Pisces, Characidae): A species complex. Braz J Genet 14:331-357.

Pereira MA, Oliveira C, Foresti F and Maistro EL (2002) Cytogenetic and nuclear DNA content analysis in Anostomidae fishes from the Sapucaí River, Minas Gerais state, Brazil. Cytologia 67:289-296.

Sato LR, Oliveira C and Foresti F (2004) Karyotype description of five species of Trichomycterus (Teleostei, Siluriformes, Trichomycteridae). Genet Mol Biol 27:45-50.

Schweizer D (1980) Simultaneous fluorescent staining of R bands and specific heterochromatic regions (DA-DAPI bands) in human chromosomes. Cytogenet Cell Genet 27:190-193.

Sumner AT (1972) A simple technique for demonstrating centromeric heterocromatin. Expl Cell Res 75:304-306.

Venere PC, Miyazawa CS and Galetti-Jr PM (1999) New cases of supernumerary chromosomes in Characiform fishes. Genet Mol Biol 22:345-349.

Wasko AP, Venere PC and Galetti-Jr PM (1996) Chromosome divergences between two sympatric characid fishes of the genus Bryconamericus. Braz J Genet 19:225-230. Associate Editor: Fausto Foresti 